\title{
Morphometric Liver Study in Adults
}

\section{Seye $\mathrm{C}^{* 1}$, Ndoye $\mathrm{JM}^{2}$, Wade $\mathbf{R}^{2}$, Mar NB ${ }^{3}$, Ndiaye $\mathrm{Ab}{ }^{2}$.}

${ }^{* 1}$ Alioune Diop University, Bambey, Senegal, Africa.

${ }^{2}$ Cheikh Anta Diop University, Dakar, Senegal, Africa.

${ }^{3}$ IbaNder Thiam University in Thiès, Senegal, Africa.

\section{ABSTRACT}

Background:The aimis to study the dimensions of the adultliver in Senegal in order to contribute to the data of the manufacture of a peri-hepaticprosthesiswrapping in the therapeuticmeans of post-traumati chemorrhagiclesions of the liver.

Materials and methods:This study involved 50 livers of anatomicalsubjectswith an averageage of 38 years. We have notedsomebiometricparameters. On the liverscollected, wemeasured the weight and some dimensions.

Results:The intermediate morphotype predominedwith $48 \%$ of cases. The dorso-petal position of the liverwasobservedin $84 \%$ of the subjects. There was no correlationbetween the morphotype of the subjects and the orientation of the visceral face of the liver. The averageliverweightwas $1410 \mathrm{~g}$. The average transverse diameterwas $25.77 \mathrm{~cm}$ while the antero-posteriordiameter of the right lobe was $16 \mathrm{~cm}$. The sagittal circumference of the liver in the sicklecell ligament wassignificantlylowerthanthosemeasured at the right and left lobes. The sagittal circumferences of the liver in the Breviligneoussubjectwerelowerthanthose of the intermediate and long morphotype subjects.

Conclusion:The choke zone between the two lobes of the liver in the sicklecell ligament is a mooring point for the peri-hepaticwrappingprosthesis. However, this can onlybe segmental for each right and left lobe. The morphotype of the subject, however, affects the weight, thickness and sagittal circumferences of the liver, which are essential for the dimensions of a peri-hepaticprosthesis.

KEYWORDS: Livermorphometric, peri-hepaticprosthesis.

Corresponding Author: Seye Cheikh, Alioune Diop University, Bambey, Senegal, Africa. Phone : 773153569 E-Mail: seyect@yahoo.fr

Access this Article online Journal Information \begin{tabular}{c|c}
\hline Quick Response code & $\begin{array}{c}\text { International Journal of Anatomy and Research } \\
\text { ISSN (E) 2321-4287 | ISSN (P) 2321-8967 }\end{array}$
\end{tabular} https://www.ijmhr.org/ijar.htm

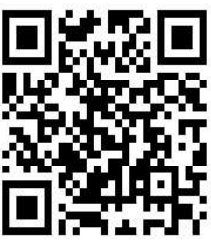

DOI: $10.16965 /$ ijar.2021.134
DOI-Prefix: https://dx.doi.org/10.16965/ijar

(cc) $\mathrm{Er}-\mathrm{Ne}-\mathrm{sh}$

\section{Article Information}

Received: 25 Mar 2021

Peer Review: 26 Mar 2021

Revised: None
Accepted: 14 Jun 2021

Published (O): 05 Aug 2021

Published (P): 05 Sep 2021

\section{INTRODUCTION}

The liver is a firm but fragile organ whose complex post-traumatic wounds requiring hemostasis are no longer sutured. However, because of its malleability and its ability to mold itself on the anatomical structures of the neighbourhood, the liver endures harmonious compressions in case of trauma [1]. It has a specific morphology related to its development in the right hypochondria and escapes any geometricre presentation [2].
Its peritoneal fasteners and vascular connections theoretically impede any wrapping process. However, the manufacture of a peri-hepatic wrapping prosthesis (PPHE) capable of providing effective compression in cases of severe trauma is still possible according to the studies of Rosset and Brunet $[3,4]$. They make perihepatic poly glact in prostheses with slow resorption of a trapezoidalform, equipped with bursa sallowing effective compression of the liver parenchyma. 
There prostheses have enabled the effective treatment of 35 patients with hemorrhagic liver trauma.

In this study, we will specify the dimensions of the liver in the adult in digenous Senegalese subject. We will compare some anthropometric data of subjects to the respective morphometric elements of the livers.

This workis part of a contribution to the manufacture of liver restraint equipment indicated in the management of serious trauma of this viscera whose frequency is increasing with that of road traffic accidents and in particular their speed in Senegal. This restraint, like that of the spleen and kidney, can beprovided by a peri-hepatic envelop eprosthesis (PPHE) that meets universal standards $[3,4]$.

\section{MATERIALS AND METHODS}

This study was carried out in the necropsy room of the Bichat pavilion of the Aristide Le Dantec University Hospital Centre in Dakar.

It involved 50 livers of indigenous adult Senegalese anatomical subjects whose cause of death was neither liver disease nor liver trauma. They were 45 men and 5 women between the ages. We used the following material: a tape measure, a reporter, a knife blade suitable for a handle, a dissecting clamp, a Kelly pliers, a scissor to dissect, a scissor to cut, a wire, a scale, a Kirschner pin, a digital camera. The study looked at the biometric parameters of the subject, morphology and certain dimensions of the liver. of 18 and 80 with an averageage of 38 .

The biometric parameters noted in each anatomical subject were: sex, age, size, chest perimeter in horizontal plane passing through the nipples, abdominal perimeter in the horizontal plane passing through the umbilical, xiphoid angle (AX) usinga reporter placed on the tip of the sternum after spotting the right and left costa wnings that constituted the limits of the angle.

Depending on the value of the xiphoid angle, subjects were referred to as short if $A X$ was greater than 80 degrees, intermediate if AX was between 80 degrees and 60 degrees, and long if $A X$ was less than 60 degrees [5].
We know the orientation of the visceral face of the liver in relation to the horizontal plane. She was referred to as a ventro-petal when she looked down and forward, dorso-petal when she looked down and back, and mixed when she looked strictly down $[6,7]$.

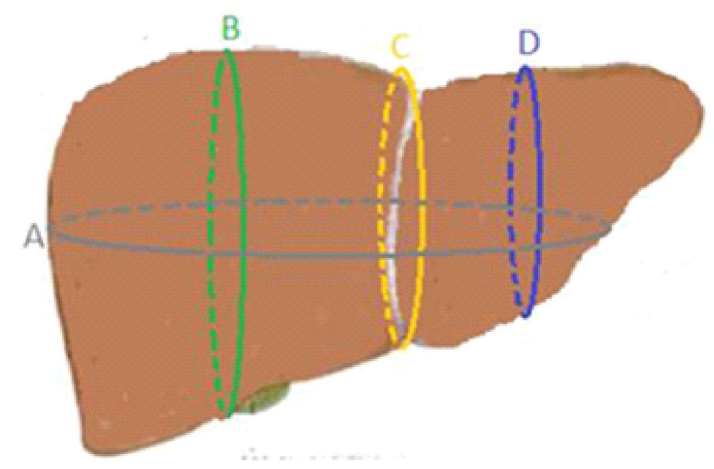

Fig.1: Anteriorview of the liver illustrating circumferences
A : Transverse liver circumference (CTF)
$B$ : Sagittal circumference of the right lobe (CSLD)

C : Sagittal cellcircumference of the sickle ligament (CSLF)

$D$ : Sagittal circumference of the left lobe (CSLG)

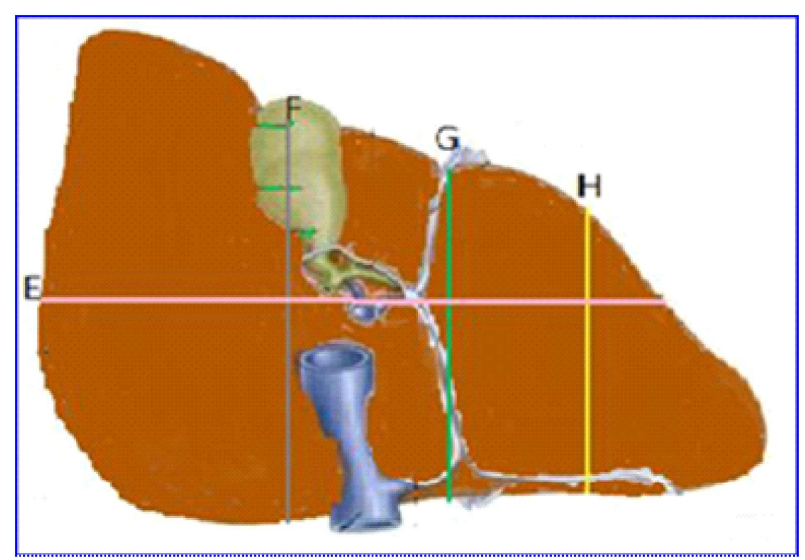

Fig.2: Lower live rview illustratingdia meters.

E: Medium transverse diameter of the liver passing through the hile of the liver

F: Medium antero-posteriordiameter of the right lobe passing the gallbladder

G: Medium antero-posteriordiameter at the level of the sicklecell ligament

$\mathrm{H}$ : Medium antero-posteriordiameter of the left lobe.

On the liver taken, rinsed with water and then weighed (in grams) we would perform (values expressed in centimeter) the following measurements (Figures 1 and 2): 
- the transverse circumference of the liver (CTF) ;

- the frontal circumference of the liver (SBB) ;

- the average transverse diameter of the liver (DTMF) passing through the hile furrow;

- the sagittal circumference of the right lobe (LTC) half way between the right extremity of the right lobe and the sickle cell ligament ;

- sagittal circumference of the sickle cell ligament (CSLF);

- the sagittal circumference of the left lobe (CSLG) half way between the left extremity of the left lobe and the sickle cell ligament ;

- the antero-posterior diameter of the right lobe (DAPLD) half way between the right extremity of the right lobe and the sickle cell ligament ;

- the antero-posterior diameter at the level of the sicklecell ligament (DAPLF) ;

- the antero-posterior diameter of the left lobe (DAPLG) half way between the left extremity of the left lobe and the sicklecell ligament;

- the maximum thickness of the right lobe (EMLD) using a Kirschner pin vertically piercing this lobe at the liverdome;

- the average thickness of the left lobe (EMLG) measured half way between the left extremity of the left lobe and the sicklecell ligament.

\section{RESULTS}

The morphotype, depending on the value of $A X$, was long in sevensubjects (14\%), intermediate in 24 subjects (48\%) and breviligne in 19 subjects (38\%). Three of the five women were of the breviline type. The average size was 179 $\mathrm{cm}$ in long subjects, $177 \mathrm{~cm}$ in intermediates and $173 \mathrm{~cm}$ in brevilles. The other external parameters are listed in Tables 1 and 2 ; these are age, height, abdominal girth (PA) and chestgirth (PT).

The weight and dimensions of the liver in men, women and the morphotype are listed in Tables 3, 4 and 5, respectively.

Table 1:Biometric Settings of Subjects.

\begin{tabular}{ccc}
\hline & Average value & Extreme values \\
\hline AGE (year) & 38 & $18-80$ \\
\hline SIZE $(\mathrm{cm})$ & 176 & $162-194$ \\
PT $(\mathrm{cm})$ & 86 & $67-105$ \\
PA (cm) & 72 & $60-97$ \\
AX (degrees) & 79 & $55-120$ \\
\hline
\end{tabular}

F:Feminine M: Male PT:chestperimeter

PA: abdominal perimeter

AX:Xiphoid angle in degrees

OFVF: orientation of the visceral face of the liver:

DP: dorso-petal

VP:ventro-petal IN:intermediate or mixed.

Table 2:maximum, minimum and average value of liverweight $(\mathrm{g})$ and size $(\mathrm{cm})$.

\begin{tabular}{ccccccccccccc}
\hline & PDS & CFF & DTM & CTF & CSLD & CSLF & CSLG & DAPLD & DAPLG & DAPLF & EMLD & EMLG \\
\hline V.moy & 1410 & 76,7 & 26 & 55,3 & 37,34 & 25,1 & 26,6 & 16,2 & 13,3 & 11,8 & 6,3 & 3,2 \\
V.max & 2100 & 96 & 30 & 62 & 44 & 31,5 & 36 & 19 & 17,5 & 16,5 & 8,5 & 5,4 \\
V.min & 900 & 63 & 21,5 & 48 & 30 & 18 & 21 & 12 & 10,5 & 9,5 & 4 & 2 \\
\hline
\end{tabular}

V.moy: average value ; Vmax:maximum value ; V.min: minimum value

Table 3: Weights and Dimensions of the Liver in Humans.

\begin{tabular}{|c|c|c|c|c|c|c|c|c|c|c|c|c|}
\hline & PDS & CFF & DTM & CTF & CSLD & CSLF & CSLG & DAPLD & DAPLG & DAPLF & EMLD & EMLG \\
\hline V.moy & 1402 & 76 & 26 & 55,2 & 37,3 & 24,8 & 26,6 & 16,1 & 13,2 & 11,6 & 6,4 & 3,2 \\
\hline V.max & 2100 & 96 & 29 & 62 & 44 & 31,5 & 36 & 19 & 17,5 & 15 & 8,5 & 4,5 \\
\hline V.min & 900 & 63 & 21,5 & 48 & 30 & 18 & 21 & 12 & 10,5 & 9 & 4,5 & 2 \\
\hline & PDS & CFF & DTM & CTF & CSLD & CSLF & CSLG & DAPLD & DAPLG & DAPLF & EMLD & EMLG \\
\hline V.moy & 1480 & 80,1 & 26,4 & 56,1 & 37,6 & 27,4 & 26,6 & 16,6 & 14,6 & 13,4 & 5,8 & 2,9 \\
\hline V.max & 1900 & 93 & 30 & 59,5 & 42 & 31,2 & 30 & 19 & 16,5 & 16,5 & 7 & 3,5 \\
\hline V.min & 1050 & 64 & 23 & 53 & 35 & 25 & 25 & 14,5 & 12,5 & 10,5 & 4 & 2 \\
\hline \multicolumn{13}{|c|}{ Table 5:Averageliverweight and size by morphotype. } \\
\hline & PDS & CFF & DTM & CTF & CSLD & CSLF & CSLG & DAPLD & DAPLG & DAPLF & EMLD & EMLG \\
\hline V.moy & 1414 & 79,6 & 26 & 55,3 & 37,6 & 25 & 26 & 16,8 & 13,3 & 11,5 & 5,6 & 2,8 \\
\hline V.max & 1373 & 76,6 & 26,3 & 55,5 & 37 & 24,5 & 26,4 & 16 & 13 & 11,6 & 6,2 & 3,2 \\
\hline V.min & 1455 & 76 & 25,5 & 55,5 & 37,5 & 26 & 27,1 & 16,1 & 13.7 & 12.1 & 6,7 & 3,3 \\
\hline
\end{tabular}




\section{DISCUSSION}

We note a real male predominance with a sex ratio of 9 ; this is far superior to the study of Pietri et al [8] and that of Rosset et al [3] who have a sex ratio of 0.85 and 1.17 respectively. This difference can be explained by the high frequency of autopsy of male victims of accidents including road traffic. The averageage of the subjectsis 38 years, which is relatively young compared to the study of Pietri et al [8] whoseaverageageis 43.5 years.

We do not note a correlation between the morphotype of the subjects and the orientation of the visceral face of the liver. The average liver weightis $1410 \mathrm{~g}$; this is not far from the average reported by Rouvière et al [9] and Kamina et al [10] which is $1500 \mathrm{~g}$ while Leguerrier [1] gives an average value between 1400 and $1500 \mathrm{~g}$. The minimum value of $900 \mathrm{~g}$ of our series is very far from that reported by Couinaud [11] which is $500 \mathrm{~g}$ in a 30-year-old woman. Depending on the morphotype of the subjects, we note that the average liver weight of the subjects of breviligneous morphotypes is higher than that of subjects of long and intermediate morphotypes. The average transverse diameter is equal to $28 \mathrm{~cm}$ in the literature $[1,9,12,13,14]$ greater than that of our study which is $25.77 \mathrm{~cm}$.

The antero-posterior diameter at the right lobe is $16 \mathrm{~cm}$ in our study consistent with all the data in the literature. $[1,12,13,14]$.

The maximum averagethickness of the right lobe is $6.33 \mathrm{~cm}$ in our study. This value is much lower than that found in the literature series where the average value is $8 \mathrm{~cm}[1,12,13,14]$. The sagittal circumference of the liver in the sickle cell ligament is significantly lower than that measured in the right and left lobe. This finding is consistent with Rosset's study [3].

In women, the sagittal circumference of the liver in the sicklecell ligament is significantly lower than that measured in the right lobe ; on the other hand, it is slightly higher than that of the left lobe. This is contrary to the results of Rosset's study [3] which argues that the circumference of the liver in the sickle cell ligament is significantly lower than the maximum sagittal circumferences of both lobes. But the low number of female cases in our study, compared to the Rosset study [3], does not allow us to beunequivocal about this contradiction. In humans, on the other hand, our results are consistent with Rosset's study [3]; but the average value of the sagittal circumference of the left lobe is very slightly higher than the average circumference of the sicklecell ligament.

The maximum thickness of the right lobe and the average thickness of the left lobe in brevillesare greater than those measured in intermediates and longlines. The sagittal circumferences of the liver in the breviline subject are less than the intermediate and long subjects. This result is consistent with Rosset's study [3].

\section{CONCLUSION}

The thickness of the right lobe is less important. The weight and liver thickness are higher in brevilles. The sagittal circumference of the liver in the sicklecell ligament was significantly lower than those measured in the right and left lobe. This is an essential data because it confirms the existence of a choke zone between the two lobes at the sicklecell ligament level in subjects that can beused to moor a peri-hepatic wrapping prosthesis. This prosthesis can only beleft or right lobar and should take into account the morphotype of the subject that affected the weight, thickness and sagittal circumferences of the liver that are essential for the dimensions of a peri-hepatic prosthesis.

\section{Conflicts of Interests: None}

\section{REFERENCES}

[1]. Leguerrier A. N.D.A. Scientific and Legal Editions, Paris, 1993;127-131.

[2]. Lanchou G, Mountain M, Pellet L.About the furrows of the convex face of the liver. Bull AssAnat, 1965;126:947-958.

[3]. Rosset E, Brunet C, Meunier B, Marie P, Di Marino $V$, Argème $M$, Farisse J. Anatomicalliver study. Development of a peri-hepaticprosthesis. SurgRadiolAnat, 1995;17:1-5.

[4]. Brunet C, Sielezneff L, Thomas P, Thirion X, Sastre $B$, Farisse J. The treatment of liver trauma from a peri-hepaticprosthesis net. Trauma J, 1994;200-204. 
[5]. Bouchet A, Spoon J. Anatomy, descriptive and functionaltopography, volume2, 2nd edition, Masson, Paris, 1991;1145p.

[6]. Didansky M. The various types of shape and position of the organs of the human body. Bull Soc anat, Paris, 1925;95:13-22.

[7]. Dufour R, Rigaud A, Dejussieu J, Soutoul J. Consideration on the orientation and morphology of the underside of the liver, theirrelationshipwith the topographical situation of the umbilical. Bull AssAnat, 1961;110:274-279.

[8]. Pietri H, Boscaini M, Berthezene P, Durbec JP, Cros R, Sarles H, DM. Hepatic Morphotypes, their statistical individualization using ultra-sonography. J Ultrasound Med 1988;189-196.

[9]. Rouvière H, Delmas A. Human Anatomy Volume II 4th edition, Masson, Paris, 1997;432-459.
[10]. Kamina P, Di Marino V.Preciseclinicalanatomy volume 2. In : Maloine, Paris ; 2002.

[11]. Couinaud C. Liver, anatomical and surgicalstudies, Masson, Paris, 1957;223-247.

[12]. Castaing D, Veilhan L A. Anatomy of the liver and bile ducts. EMC (Elsevier Masson SAS, Paris), Hepatology, 2008;39:7- 001-A-10.

[13]. Knight J M. Anatomy, trunk 1st edition, Science Medicine Flammarion, Paris, 1998;212-225.

[14]. Drake R L, Vogl. W, Mitchell A W M. Gray'sanatomy, abdomen, liver. Elsevier Masson SAS, 2006;296-299.

How to cite this article:

Seye C, Ndoye JM, Wade R, Mar NB, Ndiaye Ab. Morphometric Liver Study in Adults. Int J Anat Res 2021;9(3.2):8054-8058. DOI: 10.16965/ ijar.2021.134 